This PDF is a selection from a published volume from the National Bureau of Economic Research

Volume Title: The Rate and Direction of Inventive Activity Revisited

Volume Author/Editor: Josh Lerner and Scott Stern, editors

Volume Publisher: University of Chicago Press

Volume ISBN: 0-226-47303-1; 978-0-226-47303-1 (cloth)

Volume URL: http://www.nber.org/books/lern11-1

Conference Date: September 30 - October 2, 2010

Publication Date: March 2012

Chapter Title: Why was Rate and Direction So Important?

Chapter Authors: Nathan Rosenberg, Scott Stern

Chapter URL: http://www.nber.org/chapters/c12345

Chapter pages in book: (p. 27 - 34) 


\title{
Why Was Rate and Direction So Important?
}

\author{
Nathan Rosenberg and Scott Stern
}

One is tempted to start by saying: In the beginning was Simon Kuznets. We will not in fact start that way, because Kuznets would be more likely to point to larger social forces or institutions rather than specific individuals-he would have been more likely to point to the National Bureau of Economic Research (NBER) - where much of his early research was conducted, and where he trained and worked with his coauthors, colleagues, and former students, including Schmookler, Kendrick, Abramovitz, Fabricant, Denison, and others.

But our immediate task today is to understand how the 1962 conference volume has ended up playing such an important role in the development of the economics of innovation and technological change over the last half century. The volume includes an extremely diverse range of essays, from case studies of the organization of $\mathrm{R} \& \mathrm{D}$ to careful measurement studies to conceptual and theoretical papers, most notably Ken's paper on the nature of invention as an economic good. On their own, many of the papers would stand as important contributions to the field, and any assessment of their impact will necessarily be incomplete due to their diversity. However, our contention is to argue that the Rate and Direction volume had a separate and independent effect. Dick used the opportunity of the Rate and Direction Conference to bring together an extraordinary and diverse

Nathan Rosenberg is the Fairleigh S. Dickinson Jr. Professor of Public Policy Emeritus at Stanford University and an emeritus member of the Board of Directors of the National Bureau of Economic Research. Scott Stern is the School of Management Distinguished Professor of Technological Innovation, Entrepreneurship, and Strategic Management at the Massachusetts Institute of Technology Sloan School of Management and a research associate and director of the Innovation Policy Working Group at the National Bureau of Economic Research. 
group of scholars, and focused those scholars on identifying a systematic research program to evaluate (a) the nature of innovation as an economic good, (b) the organization of research and development organizations, and (c) the interrelationship between innovation and the dynamics of industry structure. The volume initiated a systematic research program that offered a timely counterpoint to the macroeconomic approach that equated technological change to "the residual" and treated innovation as exogenous to the economic system. The 1962 volume served a decisive role in establishing the microeconomics of innovation and technological change.

To understand this contribution, it is worthwhile to take a brief but informative review of where the field stood in the late 1950s and how it had come to that place. Kuznets (working in large part through the NBER) began, first in the 1930s and then after the war, to systematically undertake a research program focusing on the measurement of economic inputs and outputs with the objective of relating them in some fashion. While measurement had always been a part of economic science, the efforts spearheaded by Kuznets and others involved a very significant increase in the sophistication and comprehensiveness of measurement. Indeed, it is no surprise that the first chapter of the 1962 volume is by Kuznets and is entitled "Inventive Activity: Problems of Definition and Measurement." It is also unsurprising that the commentary is by Jacob Schmookler.

Most importantly, this measurement work demonstrated that the relationship between measured economic inputs (capital and labor) and outputs (gross domestic product [GDP]) was changing dramatically over time and that there was no easy explanation for this. Simply put, the measurement program spearheaded by Kuznets at the NBER illuminated the central economic fact of US economic history.

Of course, the explanatory framework for understanding these empirical findings only emerged in the mid-1950s with the seminal studies of Moses Abramovitz ([1956], reprinted in 1990) and Bob Solow (1956, 1957). Both Abramovitz and Solow highlighted that, over time, the amount of inputs required to produce a given level of output had dramatically increased (an upward shift in productivity of 2 percent per year). Simply put, they had independently discovered — or more accurately, rediscovered — the residual (Copeland 1937; Griliches 1996).

Of course, the interpretation of this increase in total factor productivity (TFP) was more controversial. In 1956, Solow introduced a simple and tractable neoclassical equilibrium growth model. The Solow model simply stated that the relationship between inputs and outputs at a point in time can be described as the "level" of technology; as such, the changing relationship between inputs and outputs can be described as "technical change." While Solow was of course aware and recognized that technical change may itself be endogenous, the model took the growth rate in technology $-A-$ to 
be exogenous. As Solow describes explicitly in his 1957 paper "Technical Change and the Aggregate Production Function," "It will be seen that I am using the term technical change as a short-hand expression for any kind of shift in the production function" (Solow 1957, 312).

Importantly, Abramovitz was less sanguine. Abramovitz memorably dubbed the residual "a measure of our ignorance." For example, in Abramovitz's review of Edward Denison's 1962 book The Sources of Economic Growth and the Alternatives Before Us. Abramovitz sharply comments that "as a residual, it is the grand legatee of all the errors of estimate embodied in the measures of national product, of inputs conventional and otherwise, and of the economies of scale . . classified under productivity growth" (Abramovitz 1990, 162). Abramovitz notes that the original estimates of the residual - with more than 85 percent of the increase in income per capita unexplained - can be attributed to various sources, including changes in the intensity of work (i.e., reduction in work hours per worker), education, appropriately measured capital inputs, and changes in technology and organization. For Abramovitz, to understand the sources of growth is not simply a measurement exercise but requires an understanding of the economic forces inducing growth, including the determinants of investment toward invention, and the relationship between those forces and measured economic aggregates (Abramovitz 1990).

Ultimately, to understand the role of innovation in economic growth, it was necessary to move beyond a "black box" approach and build a meaningful microeconomics of technical change. Dick Nelson emphasizes this point exactly in his introduction to the volume, particularly in a section entitled "The Classical Economics Approach and the Black Box." While there had been earlier attempts to make progress - for example, a 1951 Social Science Research Council meeting at Princeton University, and the impactful publications arising from Zvi Griliches doctoral dissertation, it is fair to say that the microeconomics of innovation was at that time in an embryonic state. What was missing was an economics of technical change and innovation grounded in the microeconomic, historical, and institutional environment in which invention and innovation occur. The 1962 volume was in large part the first and a particularly important salvo in that cause.

Spurred by an initiative headed by Charles Hitch, then Chairman of the Economics Department at RAND, Dick Nelson brought together a group of junior and senior scholars to focus on the rate and direction of inventive activity as a key for understanding technological change as an economic problem. The volume takes an eclectic approach, with different papers offering different methodologies - from highly descriptive papers to systematic measurement to theory. How, then, does it "hang together" and what factors made the volume so influential?

Three distinctive areas are useful to highlight: 
1. The nature of innovation as an economic good

2. The economics of the organization of research and development organizations

3. The industrial organization of innovation-intensive industries and sectors, with a particular focus on dynamics and evolution

Each of these areas is not only a central element of the microeconomics of innovation, but also one in which the 1962 volume serves as the essential starting point (or, more accurately, the starting point after Schumpeter) for the large literature that has been spawned since that time.

\section{The Nature of Innovation As an Economic Good}

The 1962 volume was a milestone in articulating how the nature of inventions and innovations as economics goods raise fundamental issues regarding appropriation, indivisibility, and uncertainty. Of course, Dick had raised these issues in his seminal 1959 paper, and issues regarding the nature of ideas as economic goods were an important area of contention among classical economists (see the penetrating summary and history of economic thought on the topic provided in Fritz Machlup's 1958 report for the US Congress, "An Economic View of the Patent System").

With that said, it is useful to consider Ken's distinctive contribution in his paper "Economic Welfare and the Allocation of Resources for Invention." Before diving into the substance, it is perhaps useful to note that, according to Google Scholar, this is Ken's third most highly referenced paper, with more than five thousand citations. Here is where Ken clearly articulates the disclosure problem: "there is a fundamental paradox in the determination of the demand for information; its value for the purchaser is not known until he has the information, but then he has in effect acquired it without cost." (Arrow 1962, 615). The traditional microeconomic notion of "willingnessto-pay" is undermined when one cannot formulate a willingness-to-pay. One cannot do so prior to having information about the idea. Most importantly, in the absence of enforceable intellectual property, once the potential buyer has the information that allows her to formulate a willingness-to-pay, the willingness-to-pay drops to zero.

Interestingly, though Machlup mentions in his 1958 essay that "Indeed, if one always cites only the 'fist and true inventor' of an argument concerning the patent system, one will rarely be able to cite an author from the 20th century" (Machlup 1958, 22), the distinctive role for intellectual property rights in enhancing the ability to negotiate and trade inventions is noted only obliquely (under the general rubric of appropriability issues).

A related contribution of the 1962 volume is the inclusion of early, persuasive empirical studies of appropriability. For example, Enos's careful study of invention and innovation in the petroleum refining industry offers 
sharp, early insights into the nature of innovation (see Rosenberg 1982, 8; Enos 2002). Enos carefully emphasizes the importance of incremental process innovations, and provides reasonable estimates of the private rates of returns (which he estimates to be quite high). The volume additionally provides evidence about the gap between the private and social rates of return. As Dick notes in the introduction, "A third major problem is that of external economies. Arrow, Kuznets, Machlup, Markham, Merrill, and Nelson all present argument or evidence that, given existing institutions, inventive activity generates values which cannot be captured by the inventor" (Nelson 1962, 14). Indeed, Arrow draws out these implications clearly in terms of the economywide incentives for research: "we expect a free enterprise economy to underinvest in innovation and research . . . because it is risky, because the product can be appropriated to only a limited extent, and because of increasing returns in use" (Arrow 1962, 619). This simple statement has certainly kept us busy.

By focusing on appropriability, the volume contrasts sharply with the treatment of innovation within the neoclassical growth literature. Not content to treat innovation as an exogenous feature of the economic environment, the papers in the volume suggest that the impact of innovation on the aggregate production function depends inherently on the microeconomic and institutional environment. For example, if a principal mechanism of appropriation is through embedding ideas into capital goods (which are protected by patent and sold at a premium), these innovations will be measured as increases in the value of the capital stock; in contrast, if the same idea is diffused for free in a perfectly competitive setting, the increase in labor productivity will be attributed to technical change. To understand the impact of innovation on economic growth, one must first understand the nature of innovation, and this requires a microeconomic orientation.

\section{The Organization of Research and Development Organizations}

Second, the 1962 volume is the first real collection of serious studies (in one place) that focuses on the economics of R\&D organizations. Several studies in the volume highlight the distinctive ways that invention and innovation are managed, from the subtle structure of incentives to the development of infrastructure that communicates complex technical ideas across large organizations.

Consider Dick's wonderful study of the development of the transistor at Bell Laboratories. The case study is unusually careful, and gives a real sense of how the scientific insight — the transistor effect—resulted in the technological innovation that we have come to know as the transistor. Dick carefully discusses the motives of the scientists, of Bell, and explains how the research project was organized. He presciently highlights key aspects of the research process that have only recently come to be appreciated: the 
role of freedom on the part of scientists, the role of research teams in creativity, and the impact of private versus public funding on both the rate and direction of research.

Perhaps most notably, Dick clearly - and perhaps for the first timearticulates the dual nature of research. Dick emphasizes the fact that a single research program may simultaneously be of fundamental scientific interest (particularly from the perspective of the researchers) yet be associated with immediate and impactful commercial application (particularly from the perspective of the private research funder). He comments: "I have a feeling that duality of interests and results is far from unusual. I wonder how many scientists - university scientists - doing basic research do not think now and then about the possible practical applications of their work. . . I have the feeling that many scientists in industrial research laboratories ... are ... internally torn about the dual nature of the research work" (Nelson 1962, 582). Of course, the dual nature of research has been at the heart of the economics of science and technology for the past half century.

Nelson's case study of the transistor is but one of seven or eight essays that begin to unpack the economics of research and development organizations. These include specific case studies of invention and innovation in the aluminum industry (Peck), the petroleum industry (Enos), DuPont (Mueller), and Bell Labs (Marschak and Nelson). These studies elucidate the impact of alternative incentive systems (e.g., whether to reward individual inventors for their discoveries), the flow of technology and knowledge within and across organizational boundaries (e.g., by examining the ultimate origin of the inventions that were ultimately impactful at companies such as DuPont), and distinctive mechanisms for appropriability, including speed, secrecy, and formal tools such as patents.

As well, the volume includes several essays emphasizing the importance of human capital and the motivation and supply of inventors, scientists, and engineers. Kuznets of course emphasized the role of education and the application of specialized researchers in his work (and also recognized the difficulties of inferring the output of innovation simply by measuring the input into innovation). Also, several papers highlight the distinctive nature of the human capital required for innovation: a preference for autonomy and freedom combined with the need to invest in specialized training at the early stages of the career.

From the perspective of the economics literature, few if any detailed case studies of the organization of research prior to this time continue to motivate theoretical and empirical research. The 1962 volume includes half a dozen, and ultimately motivated the type of systematic research seen in the work of David Mowery, Wes Cohen, and others. By bringing together a collection of careful case studies grounded in the phenomena yet attentive to economic theory, the volume offered a path for understanding the 
subtle interrelationship between the inventive process and the organization of $R \& D$ activities.

\section{Innovation and the Dynamics of Industrial Organization}

Finally, the 1962 volume is the beginning of serious industrial organization studies of strategy and innovation incentives. Notably, the section of Ken's paper entitled "Competition, Monopoly and the Incentive to Innovate" is perhaps the first important model of a nonobvious strategic effect regarding the incentives for innovative investment, and spawned the entire "patent racing" literature. Perhaps more saliently, the Arrow replacement effect serves as a powerful foundation for our modern understanding of Schumpeterian competition, and is present in the work of Aghion, Scotchmer, Segal and Whinston, and others.

More generally, the volume suggests that innovation incentives and the consequences of innovation are shaped by the microeconomic conditions of the product market. From the role of demand (as emphasized by Schmookler) to the potential for detailed strategic interaction (see Peck's detailed discussion of the market structure and innovation relationship in the aluminum industry), the 1962 volume highlighted the idea that the causes and consequences of innovation are grounded in the strategic environment in which firms and researchers operate.

\section{Concluding Thoughts}

Ultimately, the 1962 volume was among the first - and by far the most influential-volume that pointed economists toward the underlying phenomena of inventive activity and innovation as economic processes. The papers became the starting point for a microeconomic approach and lines of inquiry that have continued to this day-identifying the distinctive facets of information goods and knowledge, understanding how different research organizations are organized, and understanding the dynamic and evolutionary relationship between innovation and industrial organization.

A significant contributor to the volume's impact was its combination of detailed and concrete examples - the aluminum industry, the steel industry, Bell Labs, and so forth - with systematic measurement exercises and theoretical modeling. It is perhaps not too surprising that, by focusing a group of first-rate economists on the problems of invention and innovation, a great deal of progress was made.

Less obvious was the impact of placing the microeconomics of innovation at center stage. The volume ended up offering a constructive and ultimately quite powerful counterpoint to a more aggregate and linear view of innovation. By rendering invention as an endogenous process, one is forced to 
understand the historical context and institutional structures that motivate and facilitate the process of innovation. It is only then that the link between technological change and economic growth can be made. Looking back at the volume, it should come as no surprise that the key elements of endogenous growth theory as developed over the past two decades are the increasing returns to knowledge production, the impact of limited appropriability, and imperfect competition.

Perhaps more broadly, the volume and follow-on work have raised as many questions as they have settled. We are still involved in significant debates about the appropriate ways to fund research and development activities, the contribution of science and innovation to economic growth, and the endogenous nature of science and technological change. This anniversary conference aims to address some of questions in new ways. We look forward to that.

\section{References}

Abramovitz, M. (1989) 1990. Thinking About Growth. Cambridge: Cambridge University Press.

Arrow, K. J. 1962. "Economic Welfare and the Allocation of Resources for Invention." In The Rate and Direction of Inventive Activity, edited by R. R. Nelson, 609-26. Princeton, NJ: Princeton University Press.

Copeland, A. 1937. "Concepts of National Income." In Studies in Income and Wealth. Vol. 1, edited by the Conference on Research in Income and Wealth, 2-63. New York: National Bureau of Economic Research.

Enos, J. 2002. Technical Progress and Profits: Process Improvements in Petroleum Refining. Oxford: Oxford Institute for Energy Studies.

Griliches, Z. 1996. "The Discovery of the Residual: An Historical Note.” Journal of Economic Literature 34 (3): 1324-30.

Machlup, F. 1958. "An Economic Review of the Patent System." Washington, DC: United States Government Printing Office.

Nelson, R. R. 1962. "Introduction." In The Rate and Direction of Inventive Activity, edited by R. R. Nelson, 1-16. Princeton, NJ: Princeton University Press.

Rosenberg, N. 1982. Inside the Black Box: Technology and Economics. Cambridge: Cambridge University Press.

Solow, R. 1956. "A Contribution to the Theory of Economic Growth." Quarterly Journal of Economics 70 (1): 65-94.

1957. "Technical Change and the Aggregate Production Function." Review of Economics and Statistics 39 (3): 312-20. 